\title{
PUSAT PENGETAHUAN ALAM SEMESTA DI KOTA TUA
}

\author{
Wedo Thiodanu ${ }^{1)}$, Maria Veronica Gandha ${ }^{2)}$ \\ 1) Program Studi S1 Arsitektur, Fakultas Teknik, Universitas Tarumanagara, weithiodanu@gmail.com \\ ${ }^{2)}$ Program Studi S1 Arsitektur, Fakultas Teknik, Universitas Tarumanagara, mariag@ft.untar.ac.id
}

\begin{abstract}
Abstrak
Pesatnya perkembangan industri pariwisata di Jakarta membuat kriteria-kriteria yang diperlukan dalam sebuah objek wisata semakin lama semakin banyak, apa lagi Jakarta sebagai kota metropolitan yang menjadi pusat dari segala aktivitas dengan hiruk-pikuknya memerlukan objek wisata yang dibuat khusus dengan kriteria-kriteria masyarakat metropolis. Kriteria yang paling nampak dan sesuai dengan keseharian masyarakat metropolis adalah penggunaan teknologi. Teknologi hadir di hampir setiap aspek kehidupan masyarakat kota termasuk di bidang ilmu pengetahuan. Belum lagi dengan bertambah banyaknya jumlah generasi millennials yang hidup di Jakarta, membuat kriteria ini semakin lama semakin jelas dan dibutuhkan. Untuk itu, penulis mengkaji dan menganalisis tentang kawasan Kota Tua yang rata-rata penggunanya adalah generasi millennials dalam merancang objek wisata edukasi berbasis teknologi augmented reality (AR) dengan teori dasar tentang architourism oleh Jan Spect, teori psikologis generasi millennials, serta teori pendukung lainnya. Selain menghadirkan pengalaman belajar yang baru berbasis teknologi, proyek ini juga dapat menjadi bagian dari kawasan Kota Tua yang mengedukasi penggunanya dengan gaya modern.
\end{abstract}

Kata Kunci : generasi millennials, pariwisata, teknologi

\begin{abstract}
The rapid development of the tourism industry in Jakarta makes the criteria needed in a tourist attraction more demanding than before. Jakarta as a metropolitan city is the center of all activites with its hustle and bustle requires tourist object made specifically with the criteria of the metropolis community. The most visible and appropriate criteria of the daily life in the metropolis city is the usage of technology. Technology is present in almost every aspect of city life including knowledge and science. Not to mention the increasing number of generation of millennials living in Jakarta, making these criteria increasingly clear and needed. For this reason, the author examines and analyses Kota Tua district, which the average user in this area are millennials in designing augmented reality $(A R)$ technologybased educational attractions with a basic theory of architourism by Jan Spect, psychological theory of generation of millennials, and other supporting theories. In addition to presenting a new technology-based learning experience, this project can also be part of Kota Tua area that educates its users in a modern style.
\end{abstract}

Keyword : millennials, tourism, technology

\section{PENDAHULUAN}

Indonesia merupakan negara kepulauan (archipelagic state) terluas di dunia yang memiliki 17.504 buah pulau dengan 1.340 suku bangsa yang memiliki adat istiadat yang berbeda. (BPS 2010). Indonesia "unik" karena keberagamannya. Dari Sabang sampai Marauke menyuguhkan berbagai macam perbedaan mulai dari suku, adat istiadat.

Bahasa daerah, arsitektur sampai kuliner. Keberagaman inilah yang membuat pariwisata menjadi sektor ekonomi penting di Indonesia. Pada tahun 2009, pariwisata menempati urutan ketiga dalam hal penerimaan devisa setelah komoditi minyak dan gas bumi serta minyak kelapa sawit. Di tahun 2016, devisa dari sektor pariwisata pada 2016 sebesar US\$13,568 miliar berada di posisi kedua setelah kelapa sawit US\$. 15,965 miliar (Badan Pusat Statistik). Menurut 
Badan Pusat Statistik (BPS), sekitar 61\% turis yang datang ke Indonesia bertujuan untuk liburan, sementara $39 \%$ untuk tujuan bisnis.

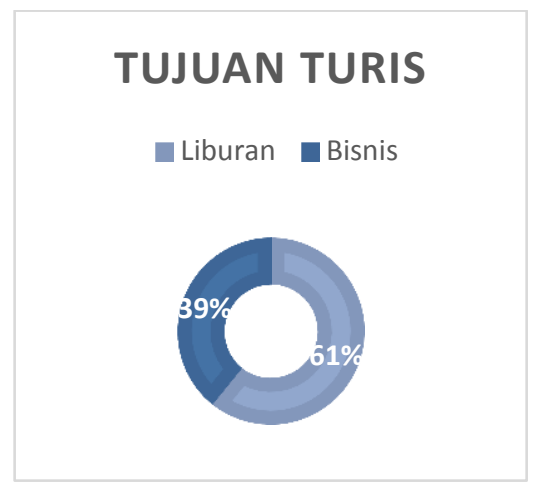

Diagram 1. Diagram Tujuan Turis yang datang ke Indonesia Sumber: Badan Pusat Statistik

Jumlah wisatawan mancanegara yang datang ke Indonesia tercatat sebanyak 264 juta orang lebih dan tumbuh sebesar 10,79\% dari tahun sebelumnya (Badan Pusat Statistik:Pariwisata 2016). Di Jakarta sendiri, jumlah turis mancanegara yang berkunjung pada tahun 2017 ada sebanyak 2,6 juta orang, sedangkan di tahun yang sama Bali dikunjungi sebanyak 4,5 juta orang. (Tim Visit Wonderful Indonesia 2018). Hal ini disebabkan oleh karakter kota Jakarta yang selalu padat dengan kesibukan rutinitas sehingga jarang untuk dijadikan destinasi liburan bagi turis. Ini berbeda dengan Bali yang berkarakter "alami" yang membuat turis ingin berlibur.

Sebagai kota metropolis, Jakarta menyuguhkan destinasi wisata berupa museum, tempat bersejarah, dan daerah pesisir yang menarik. Untuk menarik turis, dinas kebudayaan dan kepariwisataan membetuk tim Visit Wonderful Indonesia yang berfungsi untuk "menjual" kepariwisataan Indonesia dan Jakarta.

Menurut Badan Pusat Statistik, objek wisata dengan pengunjung terbanyak adalah Taman Impian Jaya Ancol yang merupakan wisata pesisir mengalahkan objek wisata sejarah. Dengan ini dapat disimpulkan bahwa turis (asing atau lokal) lebih memilih objek wisata pesirir yang artificial (buatan) dibandingkan objek wisata yang lebih bernilai sejarah. Padahal Indonesia memiliki sejarah yang beragam dan penting sehingga nilai sejarah ini dapat menjadi potensi.

Dengan kemajuan teknologi sekarang, teknologi dapat menjadi sarana yang membantu kenaikan potensi wisata sejarah karena teknologi sudah merambah ke berbagai aspek hidup manusia khususnya penghuni Jakarta.

Salah satu teknologi yang berkaitan dengan konteks ini dalah augmented reality (AR). Augmented Reality (VR) dapat menciptakan sebuah lingkungan maya baru dengan menambahkan 2D atau 3D ke realita dan membuat penggunanya merasakan pengalaman baru secara langsung. Dengan bantuan teknologi ini, bisa meningkatkan efektifitas pembelajaran materi sekolah sehingga generasi millennials metropolitan yang sudah bosan dengan metode pembelajaran sekarang dapat diberikan pilihan untuk mempelajari sejarah terbentuknya kehidupan dan alam semesta dengan asyik dan menyenangkan menggunakan teknologi augmented reality $(A R)$ ini.

\section{METODE}

Berdasarkan kuisioner digital yang dibagikan kepada generasi millennials di sekolahsekolah. Kuisioner berisikan tentang seberapa tertarik generasi millennials belajar hal yang berbau sejarah. Sejarah dipilih sebagai subjek yang ditanyakan dikarenakan beberapa hal berikut: selain belajar di sekolah, pelajaran sejarah juga dapat dilakukan di luar sekolah (studi ekskursi); sejarah memiliki sifat jauh dari teknologi dan 'kekinian'; Cara belajar materi sejarah 
di sekolah monoton dan hafalan di kebanyakan sekolah-sekolah swasta yang berkelas menengah.

Penulis mendapatkan 50 respon yang menyatakan bahwa banyak dari generasi millennials yang kurang menyukai hal yang berbau sejarah karena cara belajarnya yang membosankan. Mereka akan mulai tertarik dengan pelajaran sejarah apa bila ada cara belajar yang bersifat praktik (studi ekskursi) dan interaktif dibandingkan hafalan di kelas menggunakan buku.

Tabel 1. Tabel Hasil Survey

\begin{tabular}{|l|l|}
\hline Tidak suka dengan hal yang berbau sejarah & 34 \\
\hline Bosan saat pelajaran sejarah & 39 \\
\hline $\begin{array}{l}\text { Ada kemungkinan menjadi suka dengan } \\
\text { pelajaran sejarah }\end{array}$ & 21 \\
\hline Tidak pernah ke kawasan Kota Tua & 27 \\
\hline
\end{tabular}

Sumber: Dok. pribadi

Berdasarkan hasil survey, $70 \%$ lebih dari responden (generasi millennials) tidak suka belajar hal yang berbau sejarah karena metode pembelajaran yang membosankan. Studi ekskursi (field trip) dapat menjadi pilihan untuk mengurangi kejenuhan, tapi tidak efisien jika dilakukan secara terus menerus. Tidak efisien di anggaran sekolah dan penyerapan materi setiap anggota didik berbeda-beda. Penulis melakukan analisa berdasarkan masalah tersebut agar generasi millennials dapat lebih tertarik belajar tidak hanya hal yang berbau sejarah tapi segala hal dengan menyajikan metode belajar berbasis teknologi.

\section{DISKUSI DAN HASIL}

\section{Program}

Metode belajar menggunakan teknologi augmented reality (AR) sebagai basisnya. Untuk bisa berwisata dan menikmati program yang disediakan di proyek ini pengguna bangunan diharuskan menggunakan smartphone. Di proyek ini juga disediakan counter peminjaman smartphone di bagian installation booth untuk mempermudah pengguna yang tidak memiliki smartphone tapi ingin menggunakan bangunan ini. Ada dua jenis augmented reality (AR) yang akan disajikan pada proyek ini.

\section{AR Photobooth}

Di station ini, pengguna dapat melakukan scanning pada QR Code yang terdapat di panel station dan memunculkan AR saat mengarahkan kamera smartphone kearah green screen sebagai background untuk berfoto.

\section{Board Scan}

Di station ini, pengguna dapat melakukan scanning pada QR Code yang terdapat di panel station dan memunculkan AR pada papan untuk memunculkan informasi tambahan dari papan tersebut. Berikut adalah jenis program bangunan ini

1. Outter Space Area

Area ini merupakan awal dari seluruh perjalanan cerita terbentuknya kehidupan di alam semesta. Di area ini berisikan teori big bang, terbentuknya partikel-partikel yang membentuk planet-planet dan alam semesta.

2. Inner Space Area

Area ini merupakan awal mula kehidupan yang ada di bumi. Di area ini berisikan pengetahuan tentang makhluk hidup dari zaman pra sejarah hingga perkembangan manusia selama berjutajuta tahun. 


\section{Perpustakaan}

Perpustakaan ini berfungsi bagi mereka yang membutuhkan pengetahuan untuk melakukan tugas sekolah, kampus atau riset. Berisikan buku-buku pengetahuan mengenai alam semesta berserta isi nya. Perpustakaan ini terdiri dari 3 lantai. Lantai pertama dari perpustakaan ini berfungsi sebagai registrasi, sedangkan lantai 2 dan 3 adalah tempat berdiskusi dan membaca.

4. Kantor Pengelola

Kantor ini berfungsi sebagai tempat bekerja para pengelola bangunan ini.

\section{Pendukung}

Fungsi penunjang pada bangunan ini antara lain : Food Plaza, Coffee Shop, Retail, ATM Center

\section{Analisis Kriteria Tapak}

Dari permasalahan proyek yang melahirkan program, berikut adalah kriteria tapak yang muncul.

\section{Kepadatan tinggi}

Proyek ini merupakan objek wisata edukasi yang bertujuan untuk menarik minat masyarakat dan generasi millennials sehingga memerlukan kawasan dengan kepadatan tinggi. Kepadatan tinggi berbanding lurus dengan aktivitas yang tinggi sehingga arus manusia yang bergerak di sekitaran proyek dapat dialihkan ke tapak.

\section{Kawasan Bersejarah}

Proyek ini menangkat sejarah sebagai tema utama yang disuguhkan ke masyarakat karena minat masyarakat yang kurang dengan sejarah. Media yang digunakan dalam proyek ini adalah teknologi virtual sehingga kawasan bersejarah menjadi perlu sebagai kawasan proyek agar pengguna dapat merasakan sejarah secara realita.

\section{Kawasan yang "kekinian" bagi generasi millennials}

Karena generasi millennials merupakan generasi yang kurang tertarik dengan sejarah dan menjadi awal latar belakang proyek, kawasan yang dipilih harus memiliki status "kekinian" bagi generasi millennials untuk menggerakkan pengguna kawasan ke tapak untuk belajar.

\section{Layer utama kawasan dan di jalan primer}

Kedua kriteria ini dibutuhkan dalam proyek ini karena ini adalah proyek objek wisata. Dengan letak yang strategis, pengguna jalan dan kawasan akan tertarik untuk datang ke tapak.

\section{Tanah Kosong}

Proyek ini menangkat sejarah dan kawasan bersejarah menjadi salah satu kriterianya. Ada baiknya tapak yang dipilih tidak merusak bangunan dan urban-fabric kawasan agar sejarah kawasan tetap

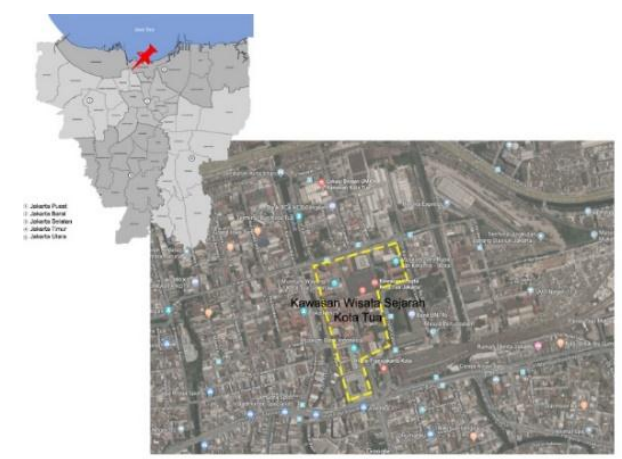

Gambar 2. Posisi Kawasan Wisata Sejarah Kota Tua Sumber: Google Earth 


\section{Berada disekitar bangunan modern}

Membangun proyek di kawasan bersejarah perlu memerhatikan gaya arsitektur bangunan sekitar, jangan sampai merusak urban-fabric kawasan. Pemilihan tapak dengan tetangga dengan arsitektur modern menjadi salah satu kriteria yang krusial.

\section{Analisis Kriteria Kawasan}

Berdasarkan kriteria tapak, kawasan kota tua adalah pilihan yang sesuai. Kota Tua merupakan kawasan objek wisata dan perkantoran dengan fasilitas yang memadai berkepadatan tinggi sehingga menunjang arus manusia yang tinggi. Kota Tua merupakan salah satu kawasan bersejarah di Jakarta yang memiliki beberapa bangunan bersejarah yang tersebar di kawasannya dan Taman Fatahillah sebagai pusat objek wisata bersejarahnya. $90 \%$ pengguna Taman Fatahillah adalah generasi millennials yang berburu foto dan suasanya setiap harinya. Puncak kepadatan area ini ada pada malam minggu.

\section{Analisis dan Desain Bangunan}

\section{Proses Pendekatan Massa Bangunan}

Proses perancangan massa bangunan dimulai dengan menganalisa kawasan Kota Tua dan mencari tapak yang diapit oleh bangunan yang lebih baru (modern) dari bangunan tua lainnya. Hal ini disebabkan oleh UDGL Kawasan Kota Tua yang tidak memperbolehkan merubuhkan bangunan tua yang sudah ada karena termasuk kategori perservasi. Bangunan proyek ini berkarakteristik blending dengan sekitar karena karakter kawasan Kota Tua yang cenderung klasik dan UDGL yang ketat sehingga tidak tepat jika karakteristik bangunan proyek ini contrast. Secara bentuk, gubahan massa bangunan berbentuk kotak, simetris, dan geometris karena mengikuti urban fabric kawasan yang didominasi oleh bangunan tua. Selain itu dikarenakan fungsi bangunan yang memiliki tipologi seperti museum yang memerlukan daya tampung yang banyak baik untuk pengguna ataupun barang yang dipamerkan.

\section{Proses Terbentuknya Massing}

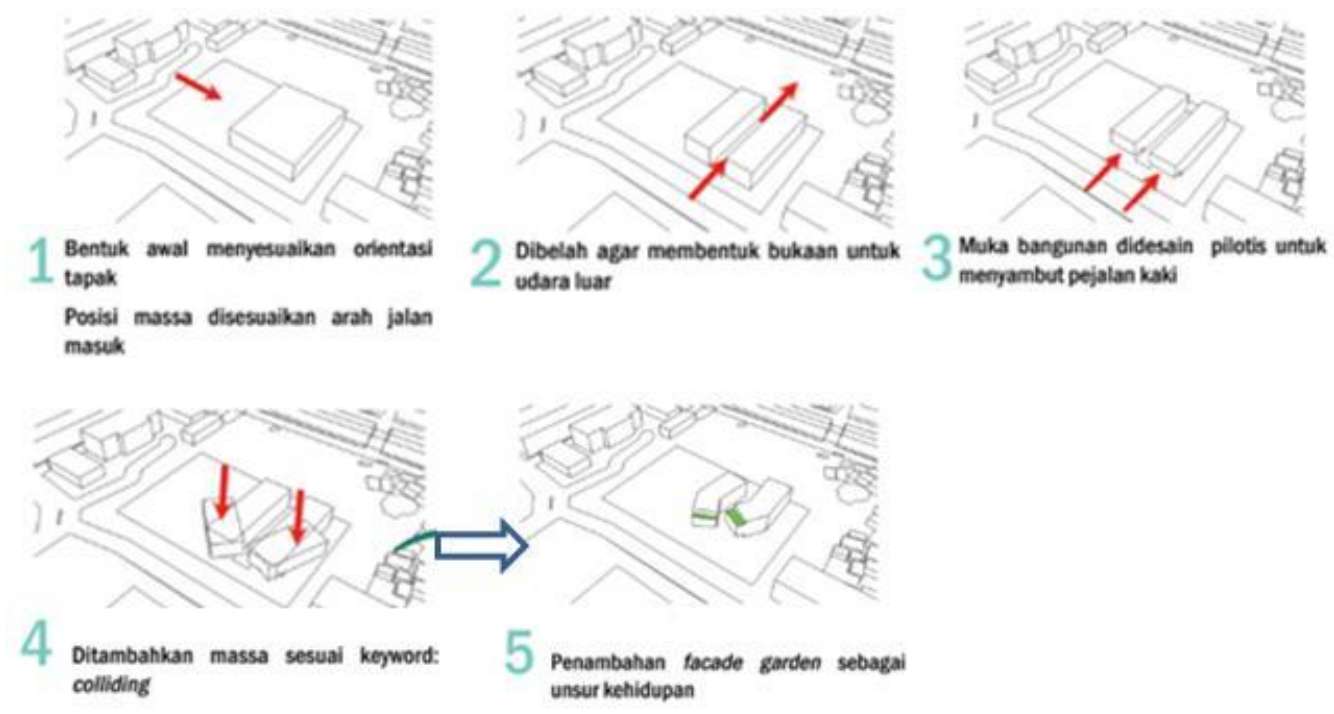

Gambar 3. Proses pembentukan massa bangunan Sumber: Dok. pribadi

Massa bangunan di letakkan berjauhan dari entrance ke tapak agar mempermudah akses masuk kendaraan bermotor. Terdiri dari dua massa yang dihubungkan dengan skybridge, hal ini dilakukan agar pengudaraan alami dapat terasa bagi pengguna karena Indonesia memiliki iklim tropis. Bagian muka bangunan didesain pilotis untuk menyambut pengguna yang berjalan kaki dari Taman Fatahillah dan sekitarnya. Ditambahkan massa lainnya agar konsep 
colliding nampak pada massa bangunan secara kasat mata dan menimbulkan karakter eye catching. Pada façade bangunan ditaman vertical garden sebagai unsur kehidupan.

Proses pembentukan massa diatas berdasarkan analisa kawasan, tapak, dan eye catchy. Untuk menarik pegunjung dan wisatawan diperlukan sifat eye catchy pada bangunan. Penambahan panel dan vertical garden dilakukan untuk memunculkan karakter unik dan eye catchy bagi pengguna kawasan.

\section{Konsep Bangunan}

Konsep dari bangunan ini adalah Colliding (tubrukan). Program dari bangunan ini adalah edukasi mengenai proses terbentuknya alam semesta, kehidupan, beserta isinya. Semuanya meledak. Ledakan itu menghasilkan partikel-partikel yang masih bersuhu tinggi. Seiring berjalannya waktu, suhu partikel-partikel tersebut mulai turun dan mereka Mulai bersatu, bertubrukan dan membentuk partikel baru.

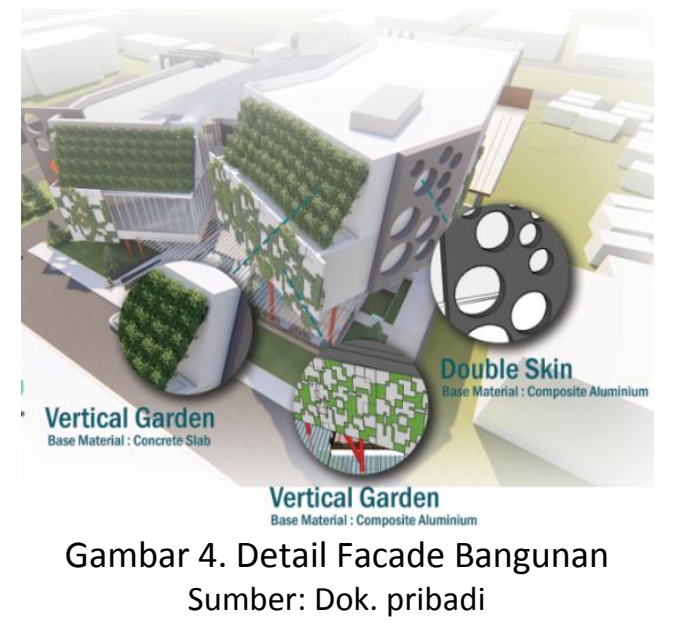

Karena tubrukan itulah terbentuk partikel baru yang menjadi awal dari terbentuknya planet dan kehidupan. Konsep diaplikasikan pada massa bangunan, facade bangunan, dan alur pengguna didalam bangunan. Pada massa bangunan, terlihat tubrukan dari dua geometri yang membentuk geometri baru. Hal ini menggambarkan terciptanya sebuah partikel baru karena mereka saling bertubrukan dan bersatu. Pada facade bangunan, terlihat panel aluminium yang bolong-bolong akibat tubrukan geometri balok dengan silinder. Desain vertical garden pada facade juga memiliki pattern tubrukan antar kotak yang membentuk bentuk baru.

\section{KESIMPULAN DAN SARAN}

Proyek berjudul "PUSAT PENGETAHUAN ALAM SEMESTA DI KOTA TUA". Proyek ini merupakan objek wisata edukasi. Dapat menjadi bagian dari kawasan Kota Tua yang mengedukasi generasi millennials yang menggunakan kawasan ini. Menjadi salah satu pilihan cara belajar baru yang memanfaatkan teknologi. Proyek ini menawarkan pengalaman baru dalam berwisata karena menggunakan smartphone dan teknologi sebagai media utama. Materi yang disuguhkan adalah proses terbentuknya alam semesta dari teori big bang sampai kehidupan di bumi sekarang. Terdapat tiga program utama, yaitu (1) Outterspace Area, (2) Innerspace Area, dan (3) Perpustakaan. Program pendukungnya antara lain (1) Kantor pengelola, (2) Coffee shop, (3) ATM Center, (4) Food Plaza dan (5) Retail.

\section{UCAPAN TERIMA KASIH}

Puji Syukur kepada Tuhan Yang Maha Esa atas rahmat dan berkat yang telah diberikan Nya sehingga penulis dapat menyelesaikan tulisan ilmiah yang berjudul "PUSAT PENGETAHUAN ALAM SEMESTA DI KOTA TUA / UNIVERSEPEDIA MEDIATECH". 


\section{REFERENSI}

Indonesia, A. P. (2017). Infografis Pentrasi \& Perikaku Pengguna Internet Indonesia. Indonesia. Retrieved Agustus 2018.

Agustinus Sutanto. Pedoman Mata Kuliah Studio Perancangan Arsitektur 8.26: Architourism of the Metropolis Specht.

Jan. (2014). Architectural Tourism: Building for Urban Travel Destinations.

Agolla, Joseph E.\&Henry Ongori. (2009). An Assessment of Academic Stress Among

UndergraduateStudents: The Case of University of Botswana. Educational Research and Review. Vol. 4 (2) pp. 063-070.

Misra, Ranjita dan Castillo, Linda. (2004). Academic Stress Among College Students:

Comparison of American and International Students. International Journal of Stress Management, Vol.11(2), 132-148.

Moore, Rowan. (2017). The Bilbao Effect: How Frank Gehry's Guggenheim Started a Global Craze. www.theguardian.com.

Arrauda Vioya. Tahapan Perkembangan Kawasan Metropolitan Jakarta. Jurnal Perencanaan Wilayah dan Kota, Vol. 21 No. 3, Desember 2010, hlm 215 - 226.

I Gusti Bagus Rai Utama, Bali. Artikel Pengembangan Wisata Kota Sebagai Pariwisata Masa Depan Indonesia.

Esti Maharani. (2015). Psikolog: 44 Persen Remaja Stres Hadapi Ujian.

https://republika.co.id/berita/pendidikan/eduaction/15/03/04/nkoeff-psikolog-44-persenremaja-stres-hadapi-ujian

Mahmmudin. (2010). Menciptakan Lingkungan Pembelajaran yang Kondusif

https://mahmuddin.wordpress.com/2010/02/18/menciptakan-lingkungan-pembelajaranyang-kondusif/

Jean Twenge, PhD. Generation Me : Why Today's Young Americans Are More Confident, Assertive, Entitled-and More Miserable Than Ever Before

http://www.apa.org/research/action/speaking-of-psychology/unlocking-millennials.aspx Wikipedia

https://id.wikipedia.org/wiki/Kota_Tua_Jakarta 